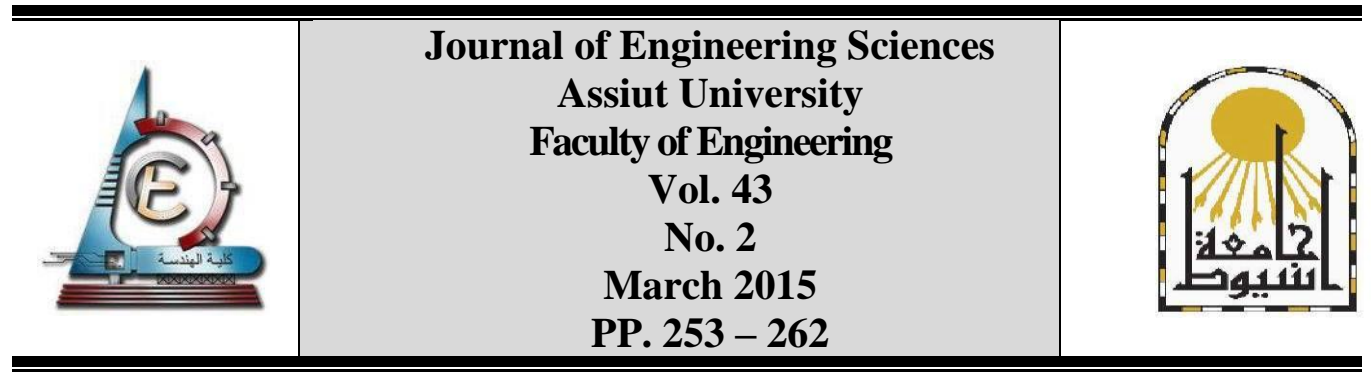

\title{
PARAMETRIC STABILITY ANALYSIS OF ROOM AND PILLAR METHOD IN DEEP COAL MINES
}

\author{
Wael Rashad Elrawy Abdellah \\ Mining \& Metallurgical Eng. Dept., Faculty of Engineering-University of Assiut, Assiut, Egypt \\ E-mail address:wre544@gmail.com \& waelabdellah@aun.edu.eg
}

(Received 14 January 2015; Accepted 24 February 2015)

\begin{abstract}
The goal of this paper is, to examine the validity of tributary area method, which is used as an empirical mean to estimate pillar dimensions, in room and pillar mines, taking into consideration a safety factor. A two-dimensional, linear elastic, finite element model (Phase 2D) is created for a simple case of a uniform pattern of room and pillar mine layout, that is lying flat $1200 \mathrm{~m}$ below ground surface. Sensitivity analysis has been done to study the effect of horizontal-to-vertical stress ratio, $\mathrm{K}$, on the maximum stress that pillar can sustain without failure. Four cases have been presented in this investigation $(K=0.5,1,1.5$ and 2$)$. The results reveal that, the maximum stress on the pillar increases as $\mathrm{K}$ increases. Alternatively, factor of safety deteriorates as mining depth (i.e., increase of $\mathrm{K}$-value) increases. The results also show that displacements/convergence expand as mining depth goes down.
\end{abstract}

Keywords: Haulage drift- Stability indicators- Numerical Modelling- Mining Step.

\section{Introduction}

Room and Pillar is so named, because pillars of coal are left standing to help support the roof of the mine. It is also called pillar and stall in which ore is extracted across a horizontal plane creating arrays of pillars and rooms. It is still very common in underground coal mines, because [1]:

- It is very flexible (i.e. relatively simple to design),

- Cheap (i.e. does not require a large capital expenditure for equipment like a long wall mining operation would),

- Highly productive (i.e. Production rates of 600 to 1,000 tons per shift per miner unit), and

- Easily mechanized.

The ore is extracted in two phases; in the first phase, pillars are left to support the roof overburden, and rooms are extracted underground. The left pillars are then partially extracted in the second phase. This technique is usually used for relatively flat-lying ore deposits. A typical design would have the entry ways (rooms) with a width of $5.75 \mathrm{~m}$ (20 ft.) and the pillars with width of 11.5 to $17.25 \mathrm{~m}$ (40 to $60 \mathrm{ft}$.) as shown in figure 1 below. In some room and pillar mines, on retreat mining, the pillars are removed, allowing the 
Wael Abdellah, Parametric stability analysis of room and pillar method in deep coal ......

roof to collapse. This is called "pulling the pillars". The objective of this design is to extract the maximum amount of ore that is compatible with safe working conditions [1].

The dimensions of the rooms and pillars depend on many design factors:

- The stability of hanging wall (Roof),

- Strength of the ore in the pillars,

- Thickness of the ore deposits, and

- The mining depth.

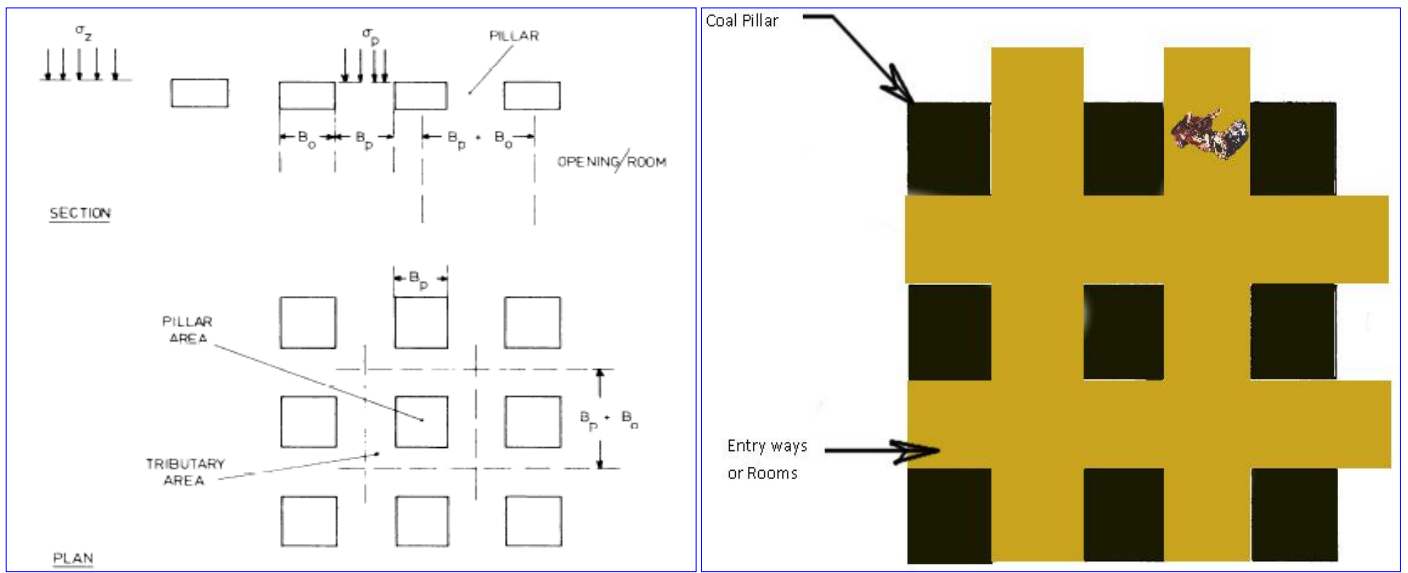

Fig. 1. Section and plan views of room and pillar mining method

If one pillar fails and surrounding pillars are unable to support the area previously supported by the failed pillar they may in turn fail. This could lead to the collapse of the whole mine. To prevent this, the mine is divided up into areas or panels. Pillars known as barrier pillars separate the panels. The barrier pillars are significantly larger than the "panel" pillars and are sized to allow them to support a significant part of the panel and prevent progressive collapse of the mine in the event of failure of the panel pillars [2].

\section{Problem definition and layout}

Figure 2, shows the layout of the modelled case study. Figure 3, represents the model set up and meshing. The studied problem is divided into four zones; sandstone (roof) and $0.5 \mathrm{~m}$ of siltyshale (immediate roof) (e.g., both are hanging wall), coal seam (e.g., $3 \mathrm{~m}$ thickness) and interbedded siltstone, shale and limestone (e.g., footwall). The geomechanical and strength properties of rock mass, used in this numerical model, are given in Table 1 below.

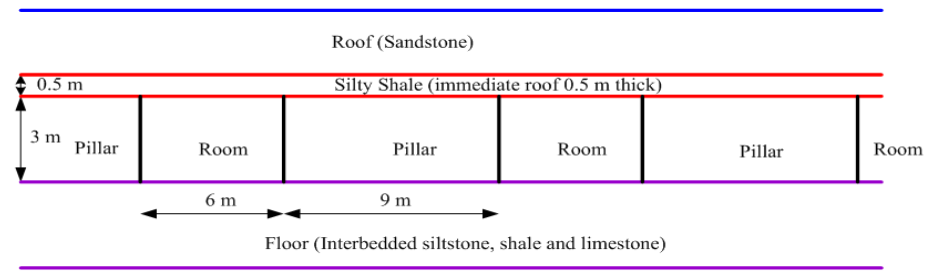

Fig. 2. Schematic representing the studied model 
Table 1.

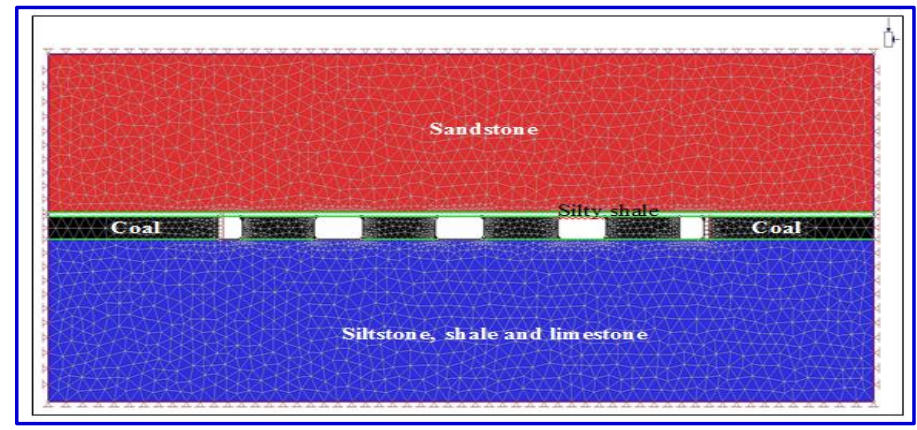

Fig. 3. Phase 2D model set up and meshing

Geomechanical rock mass properties used in the model

\begin{tabular}{|l|c|c|c|c|}
\hline \multicolumn{1}{|c|}{ Property } & $\begin{array}{c}\text { Interbedded siltstone, } \\
\text { shale and limestone } \\
\text { (Floor) }\end{array}$ & $\begin{array}{c}\text { Coal seam } \\
(3 \mathrm{~m} \text { thick) }\end{array}$ & $\begin{array}{c}\text { Silty shale } \\
\text { (Immediate roof } \\
\text { of 0.5m thick) }\end{array}$ & $\begin{array}{c}\text { Sandstone } \\
\text { (Roof) }\end{array}$ \\
\hline$\gamma, \mathrm{MN} / \mathrm{m}^{3}$ & 0.023 & 0.013 & 0.023 & 0.024 \\
\hline $\mathrm{E}, \mathrm{MPa}$ & 55100 & 3030 & 28900 & 75000 \\
\hline$v, \mathrm{Poisson}$ 's ratio & 0.22 & 0.40 & 0.28 & 0.18 \\
\hline$\sigma_{\mathrm{c}}, \mathrm{MPa}$ & 88 & 21 & 43 & 97 \\
\hline
\end{tabular}

\section{Horizontal-to-vertical stress ratio, $K$}

The ratio, $\mathrm{K}$, of average horizontal stress $\sigma_{h}$ to the vertical stress $\sigma_{v}$ is normally expressed as [3]:

$$
\mathrm{K}=\frac{\sigma_{h}}{\sigma_{v}}
$$

In the Canadian Shield, K varies nonlinearly with the depth [4-5]. At shallow depth, $K$ tends to be larger than it is in deeper mines as shown in Figure 4.

In this investigation, four scenarios have been examined with different K-values (e.g., 0.5, 1, 1.5 and 2). The mine depth is $1200 \mathrm{~m}$ below ground surface. Room width is $6 \mathrm{~m}$ and pillar width is 1.5 times the room width. The average overburden unit weight is $0.02075 \mathrm{MN} / \mathrm{m}^{3}$.

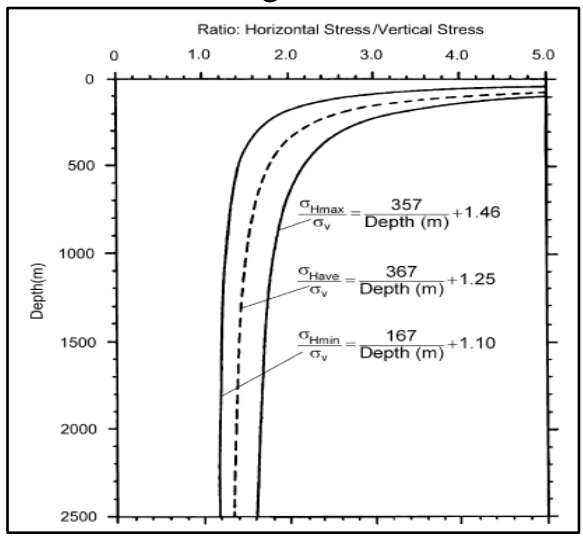

Fig. 4. Variation of K-values with depths [5-6] 


\section{Results and discussion}

The results will be presented in the next section in terms of maximum pillar stress, displacements/convergence and factor of safety.

\subsection{Stresses in pillar}

The average stresses in pillars that are of similar size and are located in a regular pattern can be estimated using the tributary area approach, which assumes that the weight of overburden is equally distributed among the pillars. This provides an upper limit of the pillar stress and does not consider the presence of barrier pillars or solid abutments that can reduce the average pillar stress. The conditions where the tributary area method is not valid, such as irregular pillars, limited extent of mining or variable depth of cover, numerical models can be used to estimate the average pillar stress [7]. The stress on the pillar can be calculated, as shown in Figure 5, using an empirical formula as per Equation (2) [8-9]:

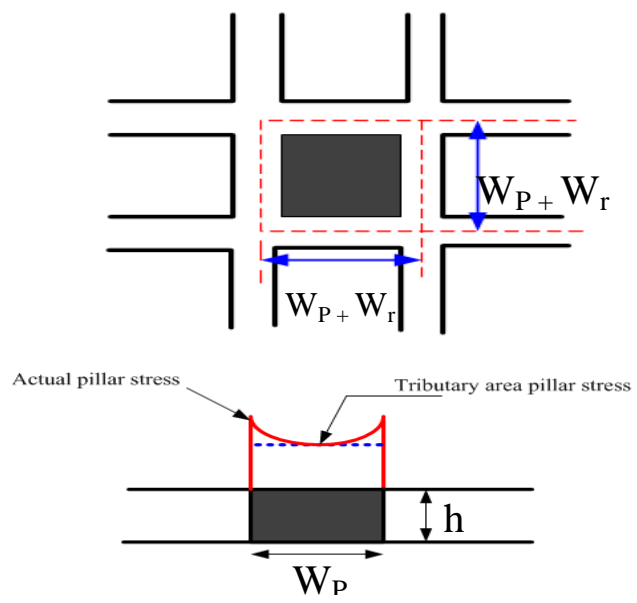

Fig. 5. Stresses in the pillar by Tributary area method

$$
\begin{aligned}
\sigma_{\mathrm{P}}=\frac{\gamma \times H\left(W_{P}+W_{r}\right)^{2}}{\mathrm{~W}_{\mathrm{P}}{ }^{2}}= & \frac{\gamma \times H}{1-R} \\
& R=1-\frac{\mathrm{W}_{\mathrm{P}}{ }^{2}}{\left(W_{P}+W_{r}\right)^{2}}
\end{aligned}
$$

Where:

$\sigma_{P}=$ Maximum stress that pillar can sustain without failure,

$\mathrm{R}=$ Extraction ratio,

$W_{P}=$ Pillar width,

$W_{r}=$ Room width,

$\mathrm{H}=$ Mining depth, and

$\gamma=$ Average unit weight of overburden.

Therefore, at $1200 \mathrm{~m}$ depth below ground surface, $W_{p}=9 \mathrm{~m}, W_{r}=6 \mathrm{~m}$ and $\gamma=0.02075$ $\mathrm{MN} / \mathrm{m}^{3}$, the stress acts on the pillar is: 


$$
\sigma_{P}=\frac{\gamma \times H\left(W_{P}+W_{r}\right)^{2}}{W_{\mathrm{P}}^{2}}=\frac{0.02075 \times 1200(9+6)^{2}}{9^{2}}=69.17 \mathrm{MPa} .
$$

The same value can be obtained through extraction ratio:

$$
\begin{gathered}
R=1-\frac{\mathrm{W}_{\mathrm{P}}{ }^{2}}{\left(W_{P}+W_{r}\right)^{2}}=1-\frac{9}{(9+6)^{2}}=0.64=64 \% \\
\sigma_{P}=\frac{\gamma \times H}{1-R}=\frac{0.02075 \times 1200}{1-0.64}=69.17 \mathrm{MPa}
\end{gathered}
$$

Table 2 summarizes the calculated and predicted (e.g., from numerical modelling) pillar stress. The simulation result depicts the maximum pillar stress at various $\mathrm{K}$-values is shown in Figure 6 below.

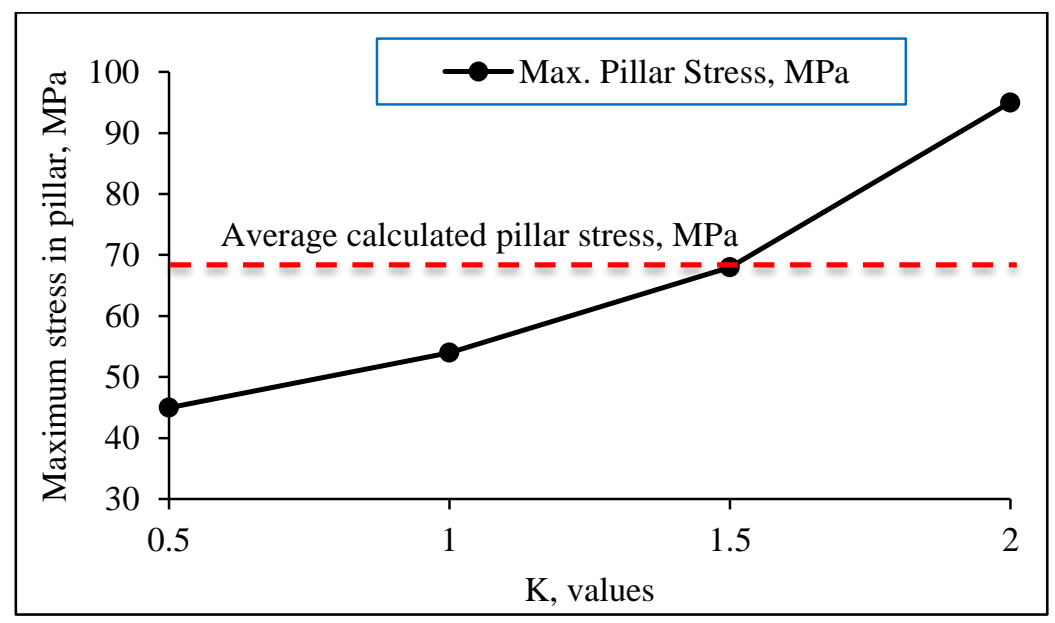

Fig. 6. Maximum pillar stress at various $\mathrm{K}$-values

\section{Table 2.}

Summary of the calculated and predicted pillar stress at various K-values

\begin{tabular}{|c|c|c|}
\hline \multirow{2}{*}{ K, value } & \multicolumn{2}{|c|}{ Maximum pillar stress, MPa } \\
\cline { 2 - 3 } & Predicted & Calculated \\
\hline 0.5 & 45 & 69.17 \\
\hline 1.0 & 54 & 69.17 \\
\hline 1.5 & 68 & 69.17 \\
\hline 2.0 & 95 & 69.17 \\
\hline
\end{tabular}

As shown in Figure 6, the empirical method gives consistent value of pillar stress. Alternatively, pillar stress is constant regardless K-value. On the other hand, pillar stress rises as $\mathrm{K}$-value increases. 


\subsection{Displacements/convergence}

Displacement/convergence is generally site specific; they depend on the rock mass stiffness properties, purpose of the underground opening and the design and code requirements. In the following, three displacement-based are introduced below:

\subsubsection{Wall convergence ratio (WCR):}

WCR is defined as the ratio of the total magnitude of the wall closure to the span of the initial drift as shown in Equation (4) [3]:

$$
\mathrm{WCR}=\frac{\mathrm{W}_{\mathrm{p}}-\mathrm{W}_{\mathrm{p}} /}{\mathrm{W}_{\mathrm{p}}} \times 100 \%=\frac{\Delta_{\max }}{\mathrm{W}_{\mathrm{p}}} \times 100 \%
$$

Where:

$W_{P}$ is the original width of the pillar and $W_{P} /$ : is the span of the pillar after deformation.

\subsubsection{Roof sag ratio ( $R S R)$}

RSR is defined as the ratio of the roof sag $(\Delta \mathrm{S})$ to the span of the pillar as given in Equation (5) [3]:

$$
\mathrm{RSR}=\frac{\Delta \mathrm{S}}{\mathrm{W}_{\mathrm{p}}} \times 100 \%
$$

Where:

$W_{p}$ is the original span of the pillar and $\Delta \mathrm{S}$ : is the roof sag.

\subsubsection{Floor heave ratio (FHR)}

FHR is defined as the ratio of floor heave $(\Delta h)$ to the span of the pillar as shown in Equation (6) [3]:

$$
\mathrm{FHR}=\frac{\Delta \mathrm{h}}{\mathrm{W}_{\mathrm{p}}} \times 100 \%
$$

Figure 7 depicts the displacement/convergence criteria at various K-values. It can be seen that, as $\mathrm{K}$ increases (e.g., horizontal stress increases) the displacement/convergence increases. The maximum displacement occurs in the wall due to high horizontal stress (e.g., at $\mathrm{K}=2$ ).

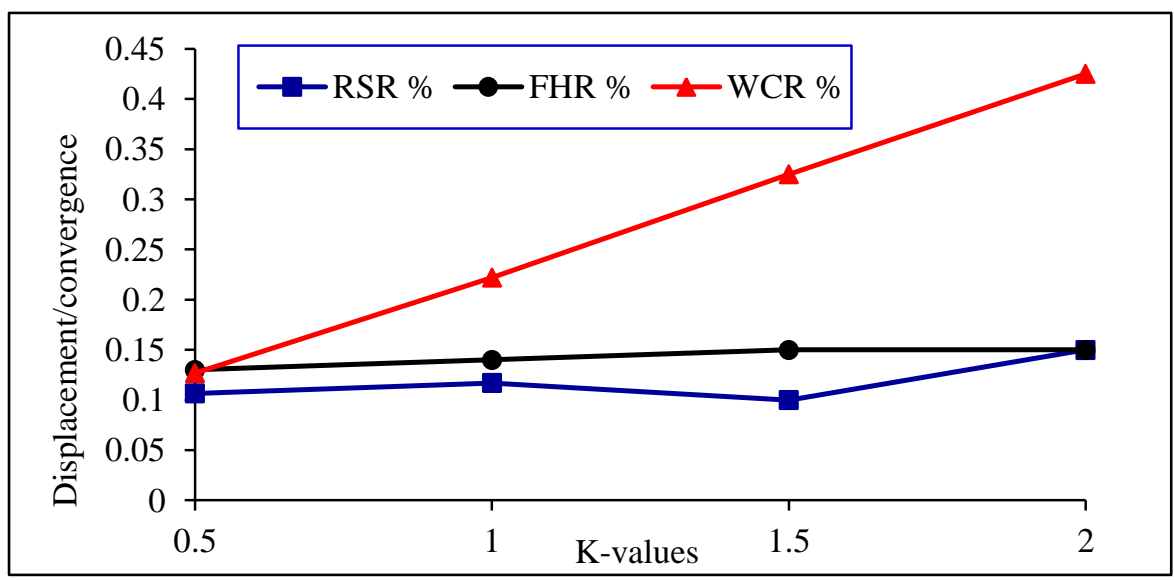

Fig.7. Displacement/convergence at various K-values 


\subsection{Factor of safety}

The stability of a pillar can be evaluated by calculating a factor of safety (FOS), which is the ratio of the pillar strength to the average stress in the pillar.

The safety factor is estimated as given in Equation (7):

FOS $=\frac{\text { Strength of the pillar }}{\text { Stress on the pillar }}=\frac{\sigma_{C F}}{\sigma_{P a}}$

Where:

FOS: factor of safety,

$\sigma_{\mathrm{CF}}:$ Strength of the pillar and

$\sigma_{\mathrm{Pa}}$ : Stress on the pillar.

The method predicts the pillar strength that can be expressed as a power equation incorporating the UCS of the rock, the pillar width $\left(\mathrm{W}_{\mathrm{P}}\right)$ and the pillar height $(\mathrm{h})$ as follows, Equation 8, [7]:

$\sigma_{C F}=0.65 \times U C S \times \frac{W p^{0.3}}{h^{0.59}}$

Therefore,

$$
\sigma_{C F}=0.65 \times 21 \times \frac{9^{0.3}}{3^{0.59}}=13.80 \mathrm{MPa}
$$

Consequently, FOS $=\frac{\text { Strength of the pillar }}{\text { Stress on the pillar }}=\frac{\sigma_{C F}}{\sigma_{P a}}=\frac{13.80}{69.17}=0.20$

Another formula used to estimate the factor of safety is given in Equations 9\&10 [10]:

FOS $=\frac{\text { Strength of the pillar }}{\text { Stress on the pillar }}=\frac{\sigma_{c} \text { of pillar }}{\sigma_{\text {Pultimate }}}$

$\sigma_{\text {Pultimate }}=\sigma_{c}+\left(\mathrm{K} \times \sigma_{3}\right)$

Where:

$\sigma_{\mathrm{c}}$ : Uniaxial compressive strength of coal,

$\mathrm{K}$ : Horizontal-to-vertical stress ratio and

$\sigma_{3}$ : Overburden stress (Vertical stress) $=\gamma \times \mathrm{H}$.

If the $\sigma_{c}$ : of the coal is $21 \mathrm{MPa}$ and $\mathrm{K}=0.5$ so, $\sigma_{\text {Pultimate }}=21+0.5 \times 0.02075 \times$ $1200=33.45 \mathrm{MPa}$.

Table 3 gives the calculated and simulated values of ultimate stress that pillar can sustain without failure and factor of safety at various K-values (based on Equations 9 \&10). The ultimate stress (e.g., predicted and calculated) act on the pillar at various Kvalues is shown in Figure 8 below. Figure 9 shows the factor of safety at various Kvalues. It can be seen from Figure 8 that, the ultimate stresses in the pillar increase as $\mathrm{K}$-value increases. But, factor of safety reduces as $\mathrm{K}$-value increases as shown in 
Wael Abdellah, Parametric stability analysis of room and pillar method in deep coal ......

Figure 9. The numerical modelling looks more conservative than empirical methods (e.g., simulated factor of safety is less than calculated).

Table 3.

Calculated and simulated ultimate stress in pillar and factor of safety at various K-values.

\begin{tabular}{|c|c|c|c|c|}
\hline \multirow{2}{*}{$\begin{array}{l}\mathrm{K}, \\
\text { value }\end{array}$} & \multicolumn{2}{|c|}{$\begin{array}{c}\text { Ultimate stress in the pillar, MPa } \\
\left(\sigma_{\text {Pultimate }}=\sigma_{c}+\mathrm{K} \times \sigma_{3}\right)\end{array}$} & \multicolumn{2}{c|}{$\begin{array}{c}\text { FOS } \\
\left(\mathrm{FOS}=\frac{\sigma_{c} \text { of pillar }}{\sigma_{\text {Pultimate }}}\right)\end{array}$} \\
\cline { 2 - 5 } & Calculated & Simulated & Calculated & Simulated \\
\hline 0.5 & $=21+0.5 * 1200 * 0.2075=33.45$ & 45 & 0.63 & 0.47 \\
\hline 1 & $=21+1 * 1200 * 0.2075=45.9$ & 54 & 0.46 & 0.39 \\
\hline 1.5 & $=21+1.5 * 1200 * 0.2075=58.35$ & 68 & 0.36 & 0.31 \\
\hline 2 & $=21+2 * 1200 * 0.2075=70.8$ & 95 & 0.30 & 0.22 \\
\hline
\end{tabular}

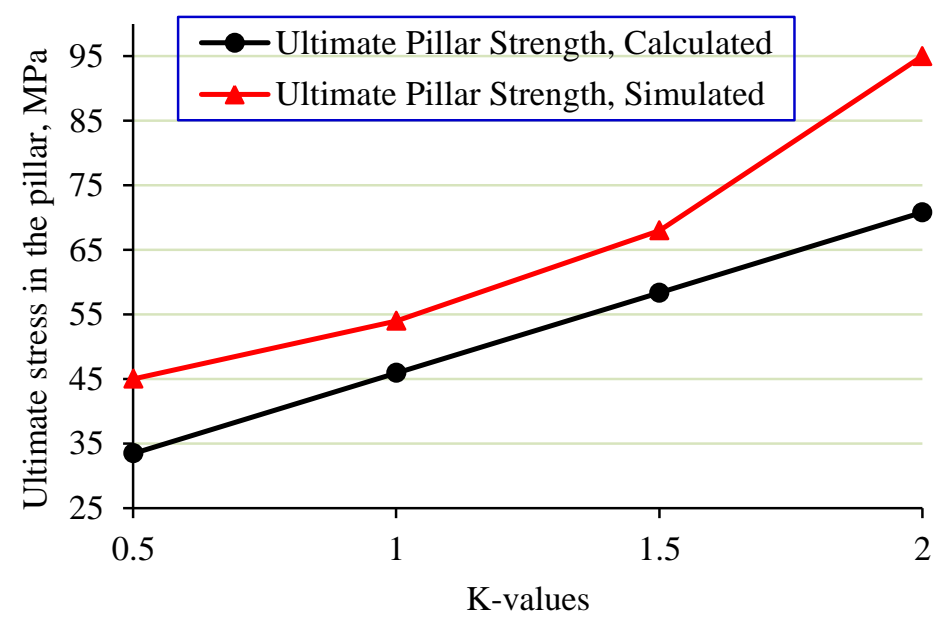

Fig. 8. Predicted and calculated ultimate stresses in the pillar at various K-values

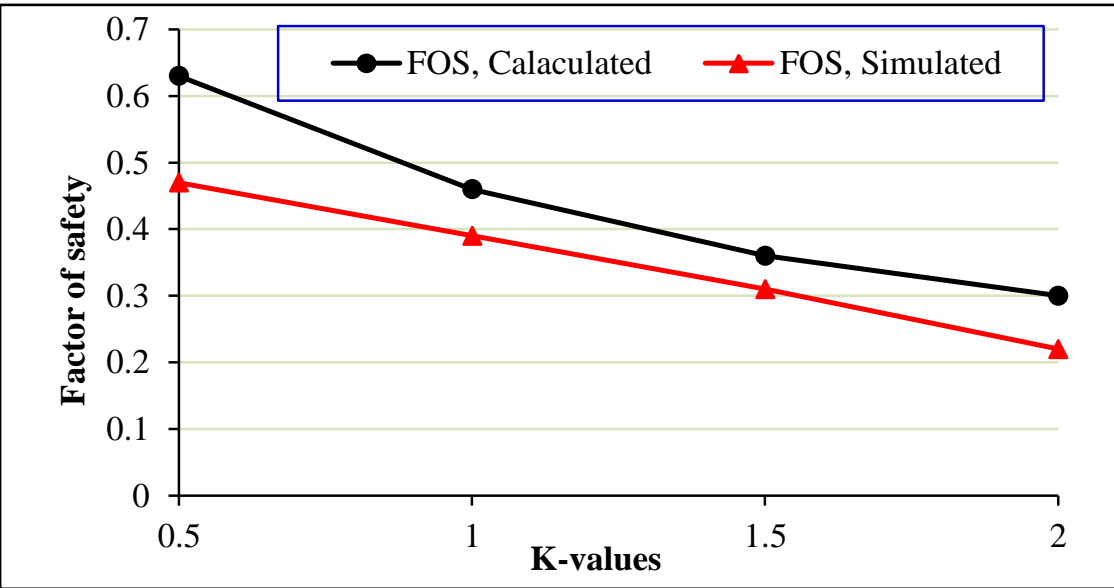

Fig. 9. Predicted and calculated factor of safety at various K-values 


\section{Conclusion}

This paper presents parametric study to evaluate the pillar stability adopting factor of safety. Room and pillar mining method has a lot of merits; such as: cheap, highly productive, easily mechanized, and relatively simple to design. Stress in a pillar is evenly distributed and equal to the original vertical geostatic stress divided by the pillar area/original area ratio. Pillar failure occurs when stress acts on pillar exceeds its compressive strength. Tributary method assumes the statement of average pillar stress; i.e. each pillar that left during excavation supports all the overlying strata that are "tributary" to their location. The results reveal that, factor of safety decreases with mining depth increases ( $\mathrm{K}$ ratio increases). The ultimate stress in pillar increases as mining depth increases (K ratio). Mining depth, Pillar width, extraction ratio, and factor of safety are most influencing factors for room and pillar mining method.

\section{REFERENCES}

[1] http://www.mine-engineer.com/mining/coal/room_pill.htm

[2] http://en.wikipedia.org/wiki/Room_and_pillar

[3] Zhang, Y. and Mitri, H.S. Elastoplastic stability analysis of mine haulage drift in the vicinity of mined stopes. International Journal of Rock Mechanics and Mining Sciences, Volume 45, Issue 4, June 2008, pp. 574-593.

[4] Brown ET, Hoek E. Trends in relationships between measured in-situ stresses and depth. Int J Rock Mech. Min. Sci. Geomech. Abstr 1978; 15(4):211.

[5] Herget G. Stress assumptions for underground excavations in the Canadian Shield. Int. J. Rock Mech. Min. Sci. Geomech. Abstr. 1987; 24(1):95-7.

[6] Henning JG. Ground control strategies at the bousquet 2 mine [MEng]. Montreal: McGill University; 1998.

[7] Esterhuizen GS, Dolinar DR. and Ellenberger JL. Pillar strength and design methodology for stone mines. In: Proceedings of the 27th international conference on ground control in mining. Morgantown WV: West Virginia University, 2008. p. 241-253.

[8] http://www.slideshare.net/sankarsulimella/pillar-design-in-coal-mines.

[9] Mullineux, F. "Coal Mining in Lancashire". In Smith, J. H. The Great Human Exploit. Phillimore \& Co. ISBN 978-0-85033-108-0, (1973).

[10] Hani Mitri,. Stability of underground openings-Course notes (MIME 521). McGill University, 2010. 


\section{دراسة تحليلية لاستقرار طريقة الحجرة والعمود فى مناجم الفحم العميقة}

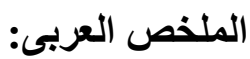

تهدف هذه الدر اسة لتقييم مدى صلاحية طريقة (tributary area method) و التى تستخدم كوسيلة تجريبية

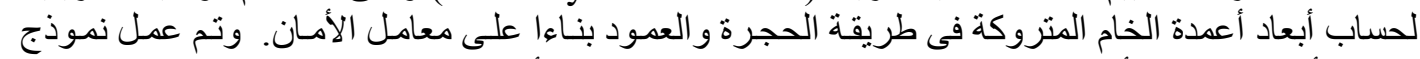

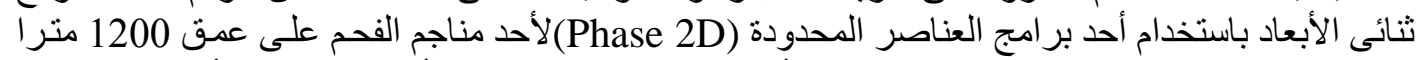

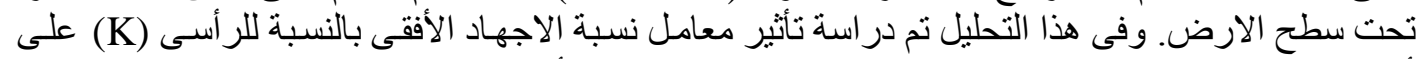

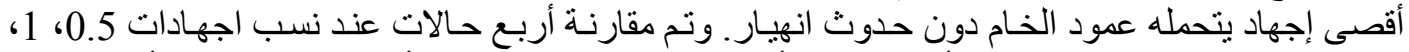

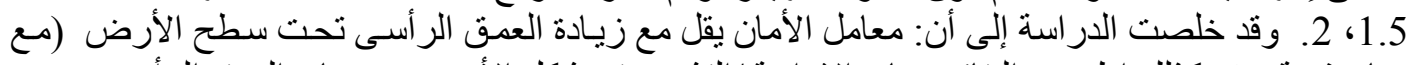

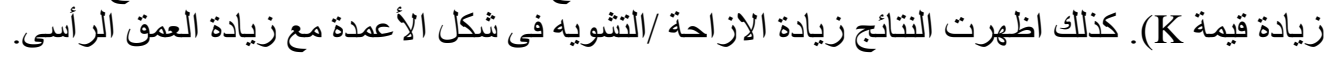

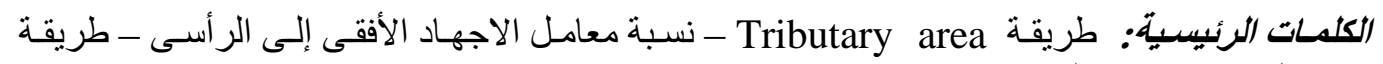

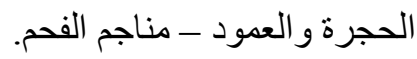

